\title{
Quantification of transient fault let-through energy within a faulted LVDC distribution network
}

\author{
Dong Wang*, Abdullah Emhemed*, Kyle Smith*, Graeme Burt*, Jawwad Zafar*, Ali Kazerooni', \\ Anthony Donoghue ${ }^{+}$
}

*University of Strathclyde, Glasgow, UK, d.wang@strath.ac.uk,

†WSP,UK, Ali.Kazerooni@wsp.com

${ }^{+}$SP Energy Networks, UK, adonoghue@spenergynetworks.co.uk

Keywords: LVDC, transient fault current, fault let-through energy, cable lifetime.

\begin{abstract}
LV direct current (LVDC) distribution systems have recently been considered as an alternative approach to electrical distribution system infrastructure as they possess the flexibility and controllability that is required to facilitate the integration of low carbon technologies (LCT). For example, energising existing LV AC cables by DC with higher voltages $(>0.4 \mathrm{kV})$ can potentially release additional power capacity on LV cables and reduce the associated thermal losses. However, converting existing AC cables for DC operation may change the cable performance under faulted conditions, resulting in a change to its lifetime. The nature of future LVDC systems can be capacitive due to the characteristic of particular customers such as battery energy storage systems (BESS) and electric vehicles (EVs). A short-circuit fault on the DC side may lead to a discharge/release of significant transient energy in LV cables which was never anticipated under traditional LVAC networks. This paper quantifies the transient DC fault let-through energy which can be imposed on existing AC cables used for DC operation, and draws conclusions on the potential impact of such phenomena on the cable performance. A detailed model of an LVDC test network with three-core LV cables is developed using PSCAD/EMTDC for simulation studies.
\end{abstract}

\section{Introduction}

Existing low voltage (LV) AC distribution networks are already under pressure to connect growing numbers of LCTs such as electric vehicles, heat pumps, micro wind turbines, and solar photovoltaic (PV) [1]. The electrification of transport and heat will add significant demand to the LV networks. For example, in the UK, under a future low carbon scenario, high penetration of electric vehicles with an annual demand of up to $90 \mathrm{TWh}$ is expected by 2050 , representing an increase of $30 \%$ from 2017 demand [2]. Also, heat pumps are expected to dominate in the UK by 2050 whilst gas boilers will fall by $70 \%$ of the UK present volume [2]. These changes to the energy system require the implementation of new solutions on LV networks to ensure electricity is delivered cost effectively.

LVDC distribution systems are being considered as an appropriate solution for facilitating the integration of LCTs such as distributed renewables, heat pumps, and EVs. The transition from existing AC to DC systems has the potential to reduce $\mathrm{LV}$ cable conductor losses, and deliver increased power capacity if existing LV cables are energised by DC with higher voltages than existing AC voltages. LVDC trial projects such as in Finland [3] and South Korea [4] have already successfully used existing LVAC cables for DC applications with voltages $\pm 750 \mathrm{~V}_{\mathrm{DC}}$. However, the key drivers for these projects are the replacement of existing ageing MVAC circuits by LVDC in rural areas with relatively low power loads. None of these trials have previously tested and discussed the performance of LV cables under extreme load conditions. Urban environments are a prime example where LVDC distribution networks can increase existing cable capacity and support the connection of higher power loads such as rapid EV chargers and heat pumps. But such a radical change in the LV network infrastructure may also impose fundamental change in the lifetime performance of LV cables under different operating conditions.

For example, LVDC can be operated with a variety of power electronic converters which are capacitive in nature compared to LVAC. Under DC fault conditions, higher transient energy will be discharged by the smoothing capacitors of converters, BESS, EV chargers, and any other associated capacitive filters. A higher power capacity LVDC distribution system, will dissapate greater amounts of energy throughout the system. This phenomenon is new to distirbution cables that were originally designed and operated on an AC distribution regime. Therefore, it is critical to understand this issue and quantify the prospective transient discharging fault let-through energy (FLTE) which can be released in a faulted LVDC system. This will help to understand the feasibility of using existing AC cables for DC, and what cable parameters may be impacted when used for DC. The transient thermal energy generated within the LV cables during DC faults must be dissipated within an allowable time frame to avoid any damage to the cables or significant degradation in its properties.

Therefore, this paper investigates fault transient responses of a faulted LVDC distribution network with high penetrations of EV chargers through detailed simulation studies. The simulation studies quantify the transient thermal energy dissipated in LV cables under DC faults at different locations. The released transient energy is compared to the thermal energy generated within an LVAC distribution network. The following sections discuss fault characteristics and responses 
of a LVDC network with different converter interfaces which are likely to be implemented in LVDC distribution systems. This is followed by a description of the model development and the selected test network, with simulation studies and associated results presented in Section 3 and Section 4 respectively. Conclusions and further research areas are provided in Section 5.

\section{LVDC fault characteristics according to converter interfaces}

This section introduces the general fault responses of LVDC with different converter topologies, such as: two-level voltage source converter (VSC); DC-DC dual active bridge (DAB) converter; and modular multilevel converter (MMC).

\subsection{Fault responses of two-level voltage source converter}

The two-level VSC is a well-known technology and has previously been utilised by a number of LVDC projects [3][4]. Figure 1 shows a layout of a two-level VSC, consisting of the main electronic switches (insulated-gate bipolar transistor (IGBT)), antiparallel diodes connected across the IGBT switches, and DC voltage smoothing capacitor at the output terminals of the converter. Under a DC pole-to-pole fault condition, the DC system will experience capacitor discharge, diode freewheeling forward-bias feeding, and AC grid feeding shown as Stage I, Stage II, and Stage III respectively in Figure 1. An example of DC fault current profile of a faulted LVDC network interfaced by two-level VSC is presented in Figure 2.

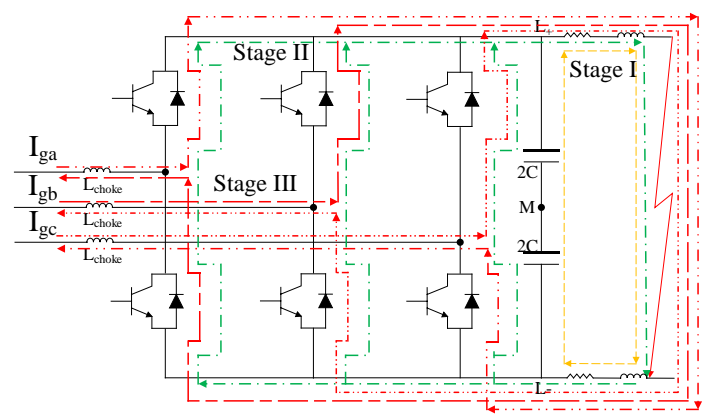

Figure 1: Fault path of two-level voltage source converter

\subsection{Fault responses of modular multilevel converter}

In comparison to two-level VSC, MMC is still at a relatively early stage of development to be deployed for LVDC distribution networks. A number of research articles have proposed MMCs with different topologies for specific LVDC distribution applications [5][6]. Under fault conditions, the MMC sub-modules can be controlled to provide positive and negative voltages. By activating the negative voltage of submodules, the output voltage of MMC can be rapidly reduced to limit the output current. Also, unlike two-level VSC, the MMC can completely block the associated capacitors' discharge and the AC grid contribution. Figure 2 shows the fault current response of a full bridge MMC with fault current limiting capability in comparison to two-level VSC. This demonstrates that, compared to the two-level VSC, the fault current of the $\mathrm{MMC}$ is extremely reduced.

\subsection{Fault responses of DC/DC dual active bridge converter}

DC/DC dual active bridge (DAB) converters have been proposed for connecting PVs, BESS, EV chargers, and electronic loads [7]. Also, it is proposed as an intermediate component within a solid state transformer (SST) which is used to convert MVDC to LVDC and provide galvanic isolation within the SST [8]. Similar to a two-level VSC, a DC/DC DAB converter has a capacitor discharge stage. However, the fault current from the DC supply side can be limited or interrupted by switching off the electronic switches on the supply side.

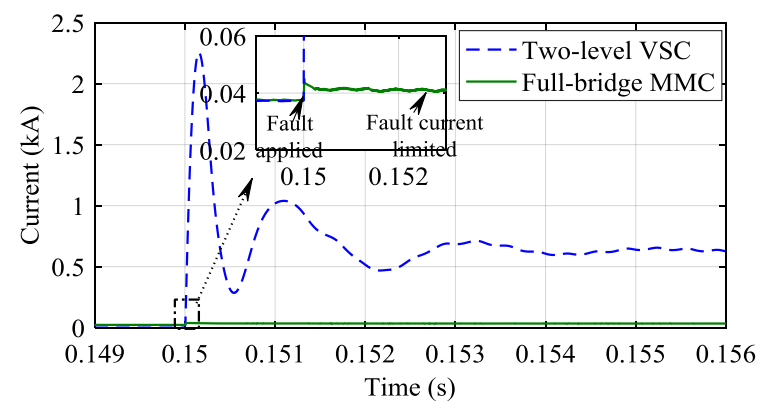

Figure 2: Examples of DC fault currents of two-level VSC and full bridge MMC

This paper aims to investigate and quantify the highest fault transient generated within existing LVAC cable specifications operated under a DC distribution regime. It is assumed that the DC network is supplied by a two-level VSC and DC/DC DAB converters are used to supply native DC customer loads in the simulation studies. An LVDC test network is designed within the PSCAD/EMTDC power system modelling environment and is presented in the following section.

\section{Modelling of an LVDC test network}

A typical UK AC MV/LV distribution network model is developed and converted to an MVAC/LVDC network as shown in Figure 3 (using the same LVAC cable specifications). The supplied loads are assumed to be DC and AC, interfaced by DC/DC and DC/AC converters from the LVDC feeders respectively. The test network model is developed as detailed in the following sub-sections.

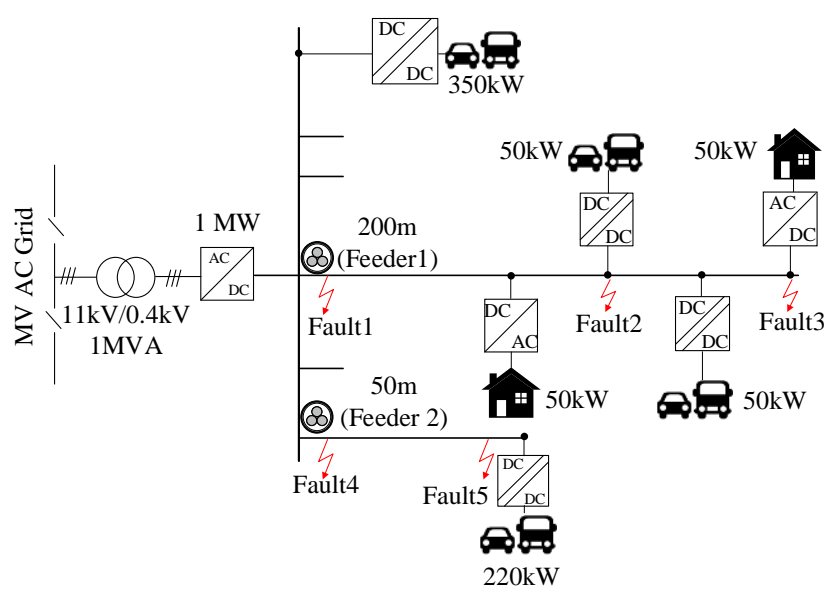

Figure 3: Layout of the modelled LVDC test network 


\subsection{AC grid supply model}

The MV grid supply point (GSP) is modelled as an $11 \mathrm{kV}$ threephase voltage source behind an equivalent impedance to provide a fault level that is equivalent to a real urban network. The fault level parameters are based on a real example of SP Energy Networks (SPEN) distribution networks [9]. Port Dundas GSP and Charles Street secondary sub-station in Glasgow, UK are used to model the AC grid supply (see Table 1 for the GSP parameters).

Table 1: Fault level parameters used for the test network [9]

\begin{tabular}{|c|c|c|c|c|}
\hline \multirow{2}{*}{$\begin{array}{c}\text { Voltage } \\
(\mathbf{k V})\end{array}$} & \multirow[b]{2}{*}{$R(\Omega)$} & \multirow[b]{2}{*}{$\mathrm{X}(\mathbf{\Omega})$} & \multicolumn{2}{|c|}{ 3-Phase Fault Level } \\
\hline & & & $\begin{array}{c}\text { Peak Make } \\
(\text { kA) }\end{array}$ & $\begin{array}{c}\text { RMS Break } \\
(\mathbf{k A})\end{array}$ \\
\hline 11 & 0.0766 & 0.6587 & 24.45 & 9.14 \\
\hline
\end{tabular}

\subsection{LVAC-LVDC interface model}

A detailed two-level VSC is modelled and used as an LVACLVDC interface to convert three-phase $400 \mathrm{~V}_{\mathrm{AC}}$ to DC outputs. The DC voltages $\pm 750 \mathrm{~V}_{\mathrm{DC}}$ is considered as an output of the converter. This voltage level has been applied in several DC trails such as the LVDC research site in Finland [3] and South Korea [4] In this work, $1500 \mathrm{~V}_{\mathrm{DC}}$ is considered to test the fault transient behaviour of the LVDC at the highest voltage which can be considered as LV in DC systems as identified by the EU LV Directive (LVD) 2006/95/EC [10].

The two-level VSC model is fully controlled to provide the required DC voltages and reactive power using oriented vector control in the synchronously rotating $\mathrm{d}-\mathrm{q}$ reference frame with the well-known sinusoidal pulse width modulation (SPWM) technique. Two-level VSC has no control of the fault on the DC side. The parameters of the two-level voltage source converter model are listed in Table 2.

Table 2: Parameters of two-level VSC model [11]

\begin{tabular}{c|c}
\hline \hline \multicolumn{1}{c|}{ Parameter } & Value \\
\hline Power rating & $1.0 \mathrm{MW}$ \\
\hline Choke inductor & $0.00044 \mathrm{H}$ \\
\hline Filter capacitor & $10 \mathrm{mF}$ \\
\hline Switching frequency & $2 \mathrm{kHz}$ \\
\hline DC voltage & $\pm 750 \mathrm{~V}$ \\
\hline Reactive power & $0 \mathrm{VAR}$ \\
\hline \hline
\end{tabular}

\subsection{LV cable model}

For new LV distribution installations, a three-core combined neutral and earth (CNE) cable is widely used in the UK. The cable configuration is shown in Figure 4, and its associated five layers are listed in Table 3. When such cable is intended to be used for DC (i.e. bipolar), two of the three inner aluminium conductors can be used to provide DC positive and negative poles, and one to provide DC mid-point (M) conductor. The $\mathrm{CNE}$ layer can be used as a DC protective earthing (PE).

In the test network model, a three-core cable with $185 \mathrm{~mm}^{2}$ cross section is modelled using the Bergeron model which represents distributed inductors, capacitors, and a lumped resistor. It is available in the PSCAD/EMTDC library. The cable parameters are listed in Table 4 and are based on the information provided by SP Energy Networks [12]. Also, the PSCAD cable model as shown in Figure 5 is used to model the cable cross section that can sufficiently represent the five layers of existing three-core cables. Two feeders are modelled shown as Feeder $1(200 \mathrm{~m})$ and Feeder $2(50 \mathrm{~m})$ in Figure 3.

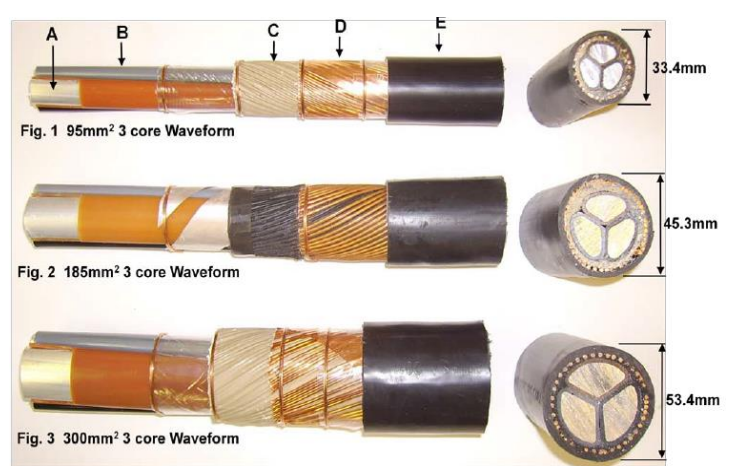

Figure 4: Three-core cable configurations [12]

Table 3: Layers of three-core cable [12]

\begin{tabular}{c||c}
\hline \hline Layer & name \\
\hline A & Inner conductor \\
\hline B & XLPE insulation \\
\hline C & Rubber bedding \\
\hline D & Copper neutral/earth wire \\
\hline E & PVC oversheath \\
\hline \hline
\end{tabular}

Table 4: Parameters of LV cable model

\begin{tabular}{c||c||c||c}
\hline \hline $\boldsymbol{\rho}($ resistivity) & $\begin{array}{c}\mathbf{r}_{\text {inner }} \\
\text { (radius) }\end{array}$ & $\begin{array}{c}\mathbf{r}_{\text {outer }} \\
\text { (radius) }\end{array}$ & $\begin{array}{c}\boldsymbol{\varepsilon} \\
\text { (permittivity) }\end{array}$ \\
\hline $\begin{array}{c}2.826 \mathrm{e}-8 \\
(\Omega \times \mathrm{m})\end{array}$ & $7.67 \mathrm{~mm}$ & $9.27 \mathrm{~mm}$ & 2.5 \\
\hline \hline
\end{tabular}

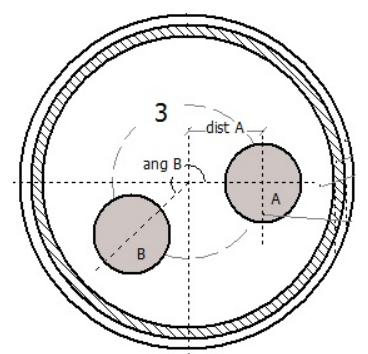

Figure 5: An example of the cable model used in PSCAD to represent the existing three-core cable cross section [13]

\subsection{End users model}

Three types of loads are modelled and connected to the LVDC feeders. These include DC fast EV chargers with power ratings of $220 \mathrm{~kW}$ and $350 \mathrm{~kW}\left(800 \mathrm{~V}_{\mathrm{DC}}\right)$, medium size DC chargers rated at $2 \times 50 \mathrm{~kW}\left(400 \mathrm{~V}_{\mathrm{DC}}\right)$, and passive $2 \times 50 \mathrm{~kW}$ AC loads. These load combinations are selected to investigate the thermal energy released by loads interfaced by different converters during LVDC transient faults. The selected EV charger power ratings and their associated DC voltages are based on real 
examples of existing technology as presented in [14]. Every EV charger model in the paper is developed as a controlled voltage source interfaced by a DC/DC DAB converter with a galvanic isolation transformer between the LVDC network and the charger load. The AC loads are modelled as constant power loads interfaced by DC/AC two-level VSCs. The parameters of the DC/DC DAB converters are listed in Table 5.

Table 5: parameters of DC/DC DAB converters with isolation transformers [15]

\begin{tabular}{c||c|c}
\hline \hline Power Rating & Choke inductance & Filter capacitor \\
\hline $350 \mathrm{~kW}$ & $0.00004 \mathrm{H}$ & $6 \mathrm{mF}$ \\
\hline $220 \mathrm{~kW}$ & $0.00005 \mathrm{H}$ & $6 \mathrm{mF}$ \\
\hline $50 \mathrm{~kW}$ & $0.0002 \mathrm{H}$ & $5 \mathrm{mF}$ \\
\hline \hline
\end{tabular}

\section{Fault transient simulation studies of LVDC distribution networks}

The key objectives of the fault transient simulation studies in this section are to: investigate the fault transient responses of an LVDC distribution network; quantify the fault let-through energy (FLTE, $\int_{0}^{t} I^{2} d t$ ) during a DC fault transient in LVAC cables; and compare the FLTE in equivalent LVDC and LVAC distribution networks during the same fault transient period. The LVAC system has the same network layout as shown in Figure 3 (without converters).

The $\pm 750 \mathrm{~V}$ LVDC distribution network, interfaced by a twolevel VSC, is tested against pole-pole faults occurring at $25 \mathrm{~m}$ intervals along Feeder 1 and Feeder 2, as shown in Figure 3. The cable dissipation energy is recorded at each fault location to fit a curve between energy and fault distance which illustrates the distribution of energy in the cables when the faults move further away from the PCC. Furthermore, the simulations are segregated between a network without EV chargers and a network containing several EV chargers as presented in Figure 3. The first transient case study considers the network without EV chargers.

\subsection{Case 1: Fault transient of a $\pm 750 \mathrm{~V}$ LVDC without $\mathrm{EV}$ chargers}

This fault transient case study considers a fault occurring close to the main bus (Fault 1), a fault occurring in the middle of Feeder 1 (Fault 2) and a fault occurring at the end of Feeder 1 (Fault 3). These fault locations are illustrated in Figure 3 and are selected as examples to demonstrate the fault current responses in Feeder 1. Figure 6 presents the fault currents in the simulated network cable when these faults occur in an LVDC distribution network without EV chargers. As the fault moves further from the main bus, towards the end of the feeder, the impedance within the fault loop is increased. Thus, the peak current in the cables decreases from $226.9 \mathrm{kA}$ to $8.2 \mathrm{kA}$. Figure 7 presents the cable section fault currents, from the fault point to the end of Feeder 1. Since there are no EV chargers and local DC/AC converters connected to the system, the fault current transient contribution is solely from cable shunt capacitors. If this is compared to the significant fault current depicted in
Figure 6, the fault current from the cable shunt capacitors is relatively small and can be neglected.

Also, compared to the equivalent LVAC distribution network, the Fault 1 transient period $(1.5 \mathrm{~ms}$ the time for capacitors discharge), produces a fault current in the LVDC system that is significantly higher than the fault current experienced in the LVAC network. It is noted that this can be up to 78.5 times greater than the fault current in the LVAC network, as shown in Figure 8. Consequently, the fault current in the LVDC network produces significantly more energy than in the equivalent LVAC network. Figure 9 illustrates the FLTE in the cables when faults are moving from the PCC to the end of Feeder 1 . It can be seen that the Fault 1 condition causes $6.3 \times 10^{6} \mathrm{~A}^{2} \mathrm{~s}$ of FLTE to pass through the early section of Feeder 1 , and this value is 1180 times greater than the FLTE that occurs in the LVAC network simulation at $1.5 \mathrm{~ms}$.

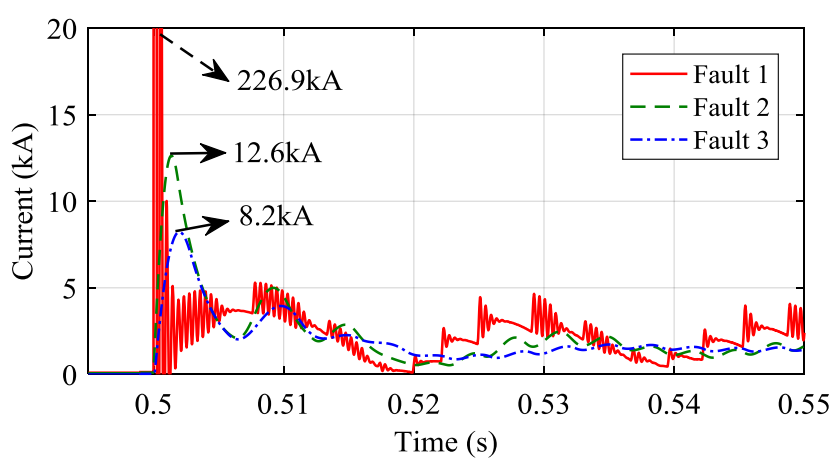

Figure 6: Fault currents in cable sections from the PCC to the fault points in case 1

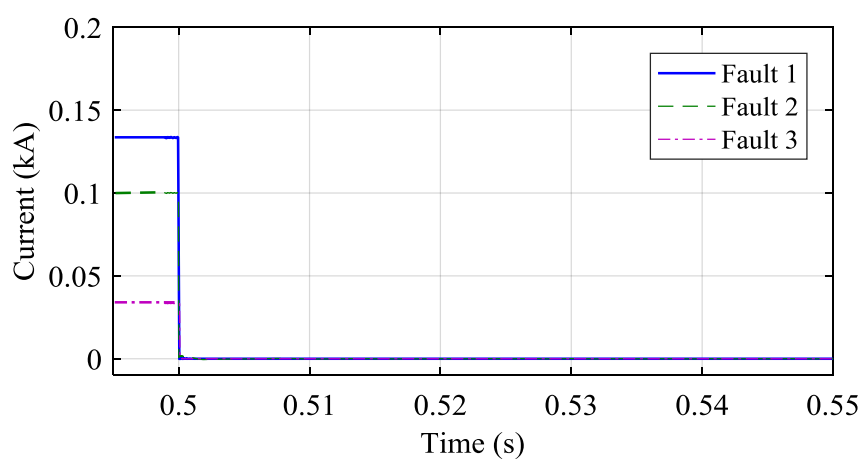

Figure 7: Fault currents in the cable sections from the end of the feeder to the fault points in case 1

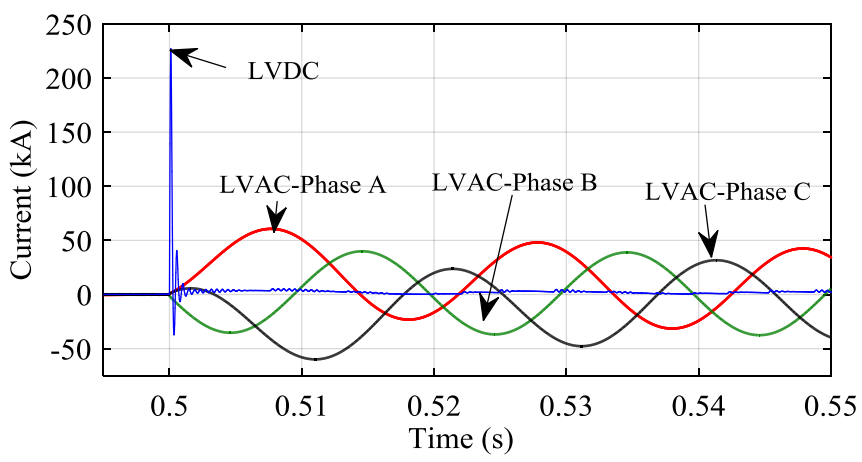

Figure 8: Fault currents from PCC to Fault 1 in LVDC and LVAC distribution networks 


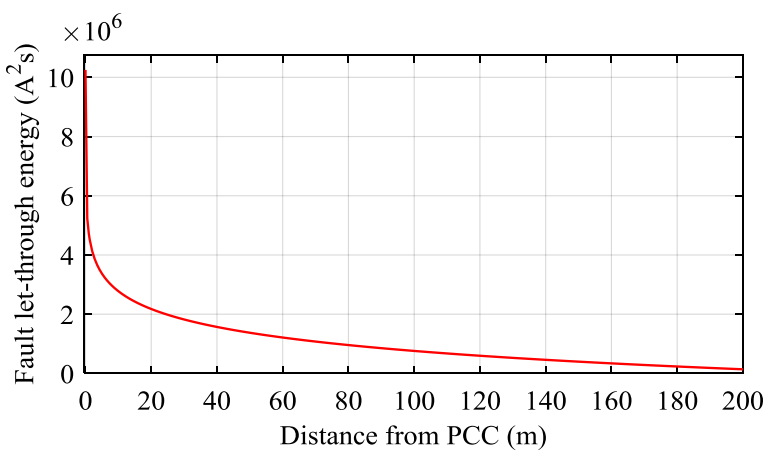

Figure 9: Fault let-through energy in Feeder 1 in case 1

\subsection{Case 2: Fault transient of a $\pm 750 \mathrm{~V}$ LVDC with distributed EV chargers}

The fault current responses of Fault 1 to Fault 3 are selected to compare the transient fault current with the previous case but now with EV chargers connected to the LVDC network. Also, the fault responses of Fault 4 (beginning of Feeder 2) and Fault 5 (end of Feeder 2) are selected to determine the fault transient energy dissipated in cables when EV chargers are conencted.

Figure 10 presents the fault currents that flow in the cable sections from the PCC to the fault points where Fault 1, Fault 2 , and Fault 3 occur. Compared to the fault currents shown in Figure 6, the peak fault currents $(292.02 \mathrm{kA}, 19.72 \mathrm{kA}$, $15.11 \mathrm{kA})$ are higher in this case when Fault 1 to Fault 3 are applied. Figure 11 shows the fault currents flowing in the cable sections. Considering the transient capacitor discharge circuits have a similar fault loop impedance, the peak fault currents $(11.08 \mathrm{kA}$ and $10.91 \mathrm{kA})$ are similar in fault conditions 1 and 2 .

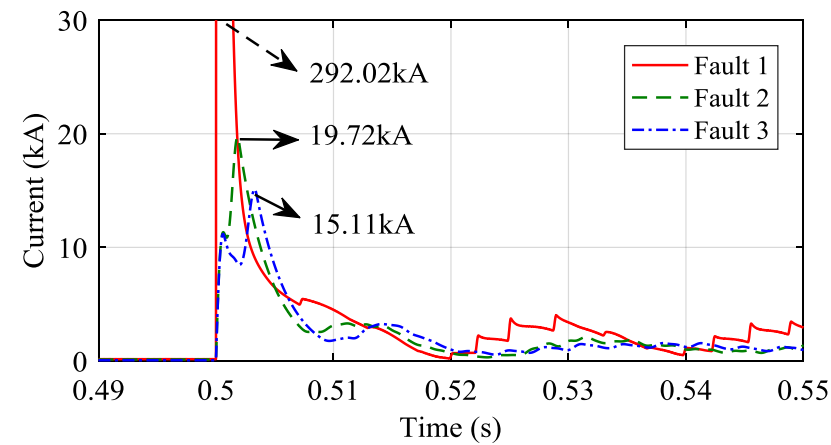

Figure 10: Fault currents in the cable sections from the PCC to the fault points in Feeder 1 in case 2

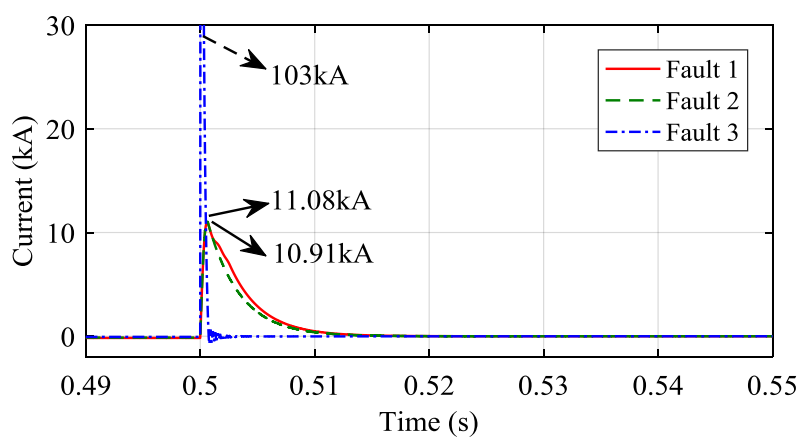

Figure 11: Fault currents in the cable sections from the fault locations to the end of Feeder 1 in case 2
Figure 12 and Figure 13 demonstrate the fault current in Feeder 2 when LVDC is connected with a number of distributed EV chargers and AC loads. When Fault 4 occurs, a significant fault (291.9kA) current flows through the early section of Feeder 2. This significant fault current generates $29.064 \times 10^{6} \mathrm{~A}^{2} \mathrm{~s}$ FLTE which is significantly higher than the FLTE generated in the LVAC system. When the fault moves towards the end of Feeder 2, the end cable section experiences significant fault current $(124.11 \mathrm{kA})$. In addition, this peak fault current generates $3.9745 \times 10^{6} \mathrm{~A}^{2} \mathrm{~s}$ FLTE. Figure 14 summarises the FLTE in the cable section from the PCC to the fault location when faults are moving from PCC to the end of Feeder 2. If the fault is sufficiently close to the main bus, significant fault energy will pass through cables. When the fault is moving away from the main bus, the cable section from the PCC to the fault location reduces. However, in this test network, as there is a rapid charger $(220 \mathrm{~kW})$ connected at the end of Feeder 2, the cable section from the fault point to the end of Feeder 2 will have more fault energy when the fault is close to the end of Feeder 2 as shown in Figure 15.

In repurposing existing $\mathrm{LVAC}$ cables to form LVDC distribution networks, where high penetrations of LCTs exist, it must be recognised that additional energy will be dissipated during a fault event in a short period of time, potentially causing "thermal shock" to the existing cables. The start and the end of cable sections are more susceptible to these spikes in thermal energy. This may cause degradation within the cables and result in a reduced operational lifetime. However, this hypothesis requires further experimental tests to investigate cable conditions under long-term DC operations.

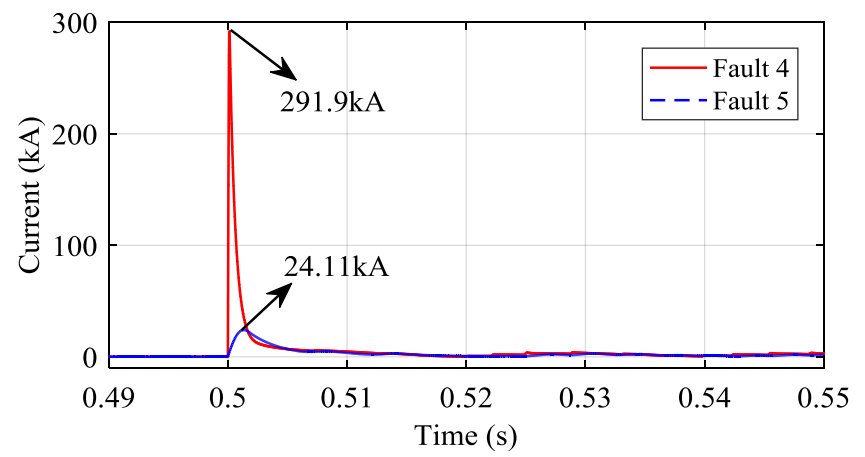

Figure 12: Fault currents in the cable sections from PCC to the fault locations in case 2

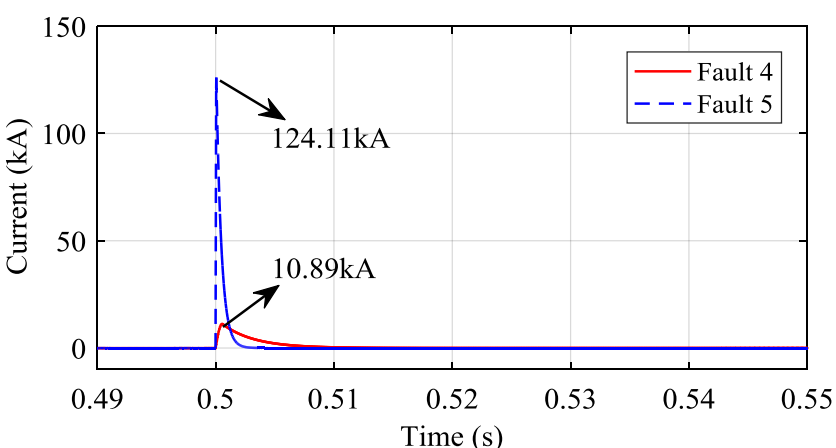

Figure 13: Fault currents in the cable sections from the fault locations to the end of Feeder 2 in case 2 


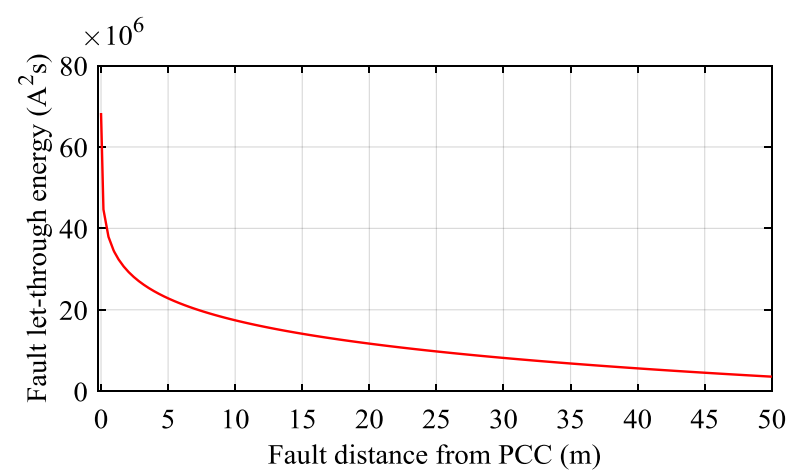

Figure 14: Fault let-through energy in the cable section of

Feeder 2 from the PCC to the fault location in case 2

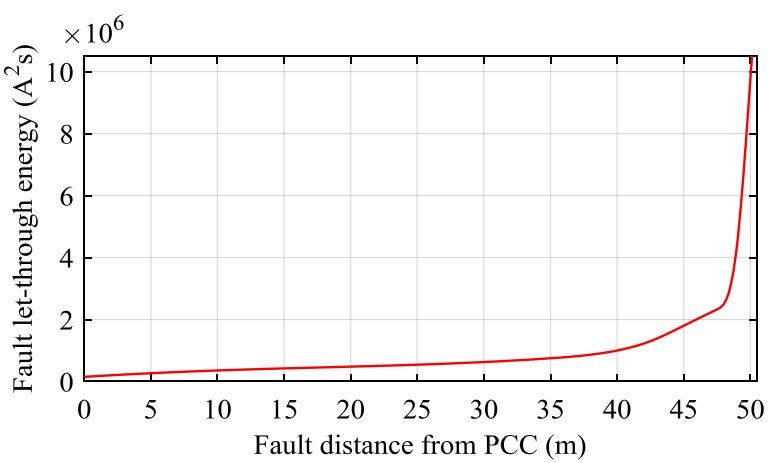

Figure 15: Fault let-through energy in the cable section from the fault point to the end of Feeder 2 in case 2

\section{Conclusions}

Converting existing LVAC distribution networks to LVDC systems offers an appealing opportunity for enhanced power capacity that may facilitate higher penetrations of LCTs such as EV charging infrastructure. If existing LV three-core cables are utilised for LVDC operation, they will experience higher energy dissipation during a fault transient period. This phenomenon is new to $\mathrm{LV}$ cables that were never designed to operate under these conditions. Therefore, this paper investigates the fault transient of a $\pm 750 \mathrm{~V}$ LVDC distribution network and quantifies the fault energy dissipated in existing three-core LVAC cables by simulating both the LVDC network and the equivalent LVAC network, with and without the presence of EV charging infrastructure.

Based on the simulation studies, it is clear that energising existing LVAC cables with LVDC, results in an insignificant fault transient contribution from shunt capacitors within existing AC cables compared to the filter capacitors of converters. In DC fault transient periods, the peak fault current in the LVDC network is higher (up to almost 80 times) than the LVAC network, this leads to the presence of high additional thermal energy compared to that experienced by existing LV cables under AC distribution. Furthermore, this paper has used the term "thermal shock" to describe the effect of the additional thermal energy that is dissipated in LV cables during a transient DC fault condition. Cable sections that are closer to converters are more likely to experience thermal shock and may therefore degrade earlier under long-term DC operation. However, further experimental testing is required to quantify the impact of thermal shock on the lifetime of LV cables under a LVDC distribution regime.

\section{Acknowledgements}

This research work was supported by the SP Energy Networks as a part of the Innovation Allowance (NIA) 'transition to low voltage DC distribution networks’ phase 1 project.

\section{References}

[1] R. Brown, et al, "Lawrence Berkeley National Laboratory Review of DC Power Distribution in Buildings : A Technology and Market Assessment," 2017.

[2] "Future Energy Scenarios 2017," 2017. [Online]. Available: http://fes.nationalgrid.com/fes-document/fes2017/.

[3] P. Nuutinen et al., "Research site for low-voltage direct current distribution in a utility - structure, functions, and operation," IEEE Trans. Smart Grid, vol. 5, no. 5, pp. 2574-2582, 2014.

[4] Y. Cho, et al., "Design and contruction of LVDC distribution site," in CIRED Workshop, 2016.

[5] A. Ghazanfari, "Control, Modulation, and Protection Strategies for Modular Multilevel Converters in Smart AC and DC Grids Applications," thesis, University of Alberta, 2017.

[6] A. Lachichi , et al., "Power Converters Design for Hybrid LV ac/dc Microgrids," in International Conference on Renewable Energy Research and Applications, 2017.

[7] L. Chang, W. Zhang, S. Xu, and K. Spence, "Review on distributed energy storage systems for utility applications," CPSS Trans. Power Electron. Appl., vol. 2, no. 4, pp. 267-276, 2017.

[8] X. She, et al., "Review of solid-state transformer technologies and their application in power distribution systems," IEEE J. Emerg. Sel. Top. Power Electron., vol. 1, no. 3, pp. 186-198, 2013.

[9] SP Energy Networks "Distribution long term development statement-Appendix 4 Fault Levels Table4," Nov 2017.

[10] Low Voltage Directive (LVD), "EU LV Legislation LVD2006/95/EC," Dec 2016.

[11] P. K. Goel, et al., "Isolated wind-hydro hybrid system using cage generators and battery storage," IEEE Trans. Ind. Electron., vol. 58, no. 4, pp. 1141-1153, 2011.

[12] SP Energy Networks, "ScottishPower Distribution Cables \& Equipment: Metal Theft," Apr 2012.

[13] "Pipe-Type Cable," 2018. [Online]. Available: https://hvdc.ca/webhelp.

[14] Porsche Engineering, "Porsche Engineering etechnology," no. 1, 2016.

[15] M. R. Banaei and R. Alizadeh, "Simulation-Based Modeling and Power Management of All-Electric Ships Based on Renewable Energy Generation Using Model Predictive Control Strategy," IEEE Intell. Transp. Syst. Mag., vol. 8, no. 2, pp. 90-103, 2016. 